Discussion

\title{
A Reassessment of the Marrubium Vulgare L. Herb's Potential Role in Diabetes Mellitus Type 2: First Results Guide the Investigation toward New Horizons
}

\author{
Javier Rodríguez Villanueva ${ }^{1, *} \mathbb{1}$, Jorge Martín Esteban ${ }^{2}$ and Laura Rodríguez Villanueva ${ }^{3}$ \\ 1 Biomedical Sciences Department, Pharmacy and Pharmaceutical Technology Unit, Faculty of Pharmacy, \\ University of Alcalá, Ctra. de Madrid-Barcelona (Autovía A2) Km. \\ 33,600, 28805 Alcalá de Henares, Madrid, Spain \\ 2 Phytotherapy Faculty, University of Barcelona, Gran Via de les Corts Catalanes, 585, 08007 Barcelona, Spain; \\ jorgemartinesteban@gmail.com \\ 3 Faculty of Pharmacy, University of Alcalá, Ctra. de Madrid-Barcelona (Autovía A2) Km. \\ 33,600 28805 Alcalá de Henares, Madrid, Spain; lau95.rv@gmail.com \\ * Correspondence: therealworldvsme@hotmail.com; Tel.: +34-91-347-41-58
}

Received: 12 July 2017; Accepted: 1 August 2017; Published: 2 August 2017

\begin{abstract}
Despite the wide variety of pharmacological activities described for the Marrubium vulgare L. herb, amazingly, only one clinical trial can be found in scientific literature. It was designed for the evaluation of its antidiabetic activity. Worse, the outcomes of this trial were contradictory to what previous in vivo mice assays had concluded. Therefore, should Marrubium vulgare be ruled out due to its lack of therapeutic potential in diabetes? The authors suggest a reevaluation of the clinical trial methodology to establish valid and final results.
\end{abstract}

Keywords: Marrubium vulgare L. herb; diabetes mellitus type 2; clinical trial; methodology

\section{Introduction}

Marrubium L. (Lamiaceae) has about forty species, generally distributed in temperate regions of Central and Western Asia, North Africa, Europe, and South America. Generally, these plants are large annual or perennial shrubs [1]. The furane labdane diterpene marrubiin is assumed to be the chemotaxonomic marker among the various species of the Marrubium genus. Generally, marrubiin is isolated from dried whole plants of Marrubium vulgare Linn (white/common horehound, hoarhound, marriout, maromba, marroio-branco, or marrubio) in a proportion of $0.3-0.7 \%$ [2]. M. vulgare L., commonly known as "white horehound" can be identified as a robust perennial herb, with densely cottony stems and white flowers [3].

Researchers have tried to support the biological activities described for the M. vulgare L. herb (for an extended analysis, see Reference [4] and Figure 1) by the isolation and identification of biologically active phytochemicals such as diterpenes (marrubiin and related compounds), flavonoids (luteolin, apigenin, ladanein, quercetin, isoquercitrin, chrysoeriol, or vitexin), phenylpropanoid esters (including acteoside (or verbascoside), forsythoside B, arenarioside, ballotetroside, alyssonoide, marruboside, and acethyl marruboside), tannins (such as proanthocyanidins, catechin and epicatechin, condensed tannins), and sterols [5]. 

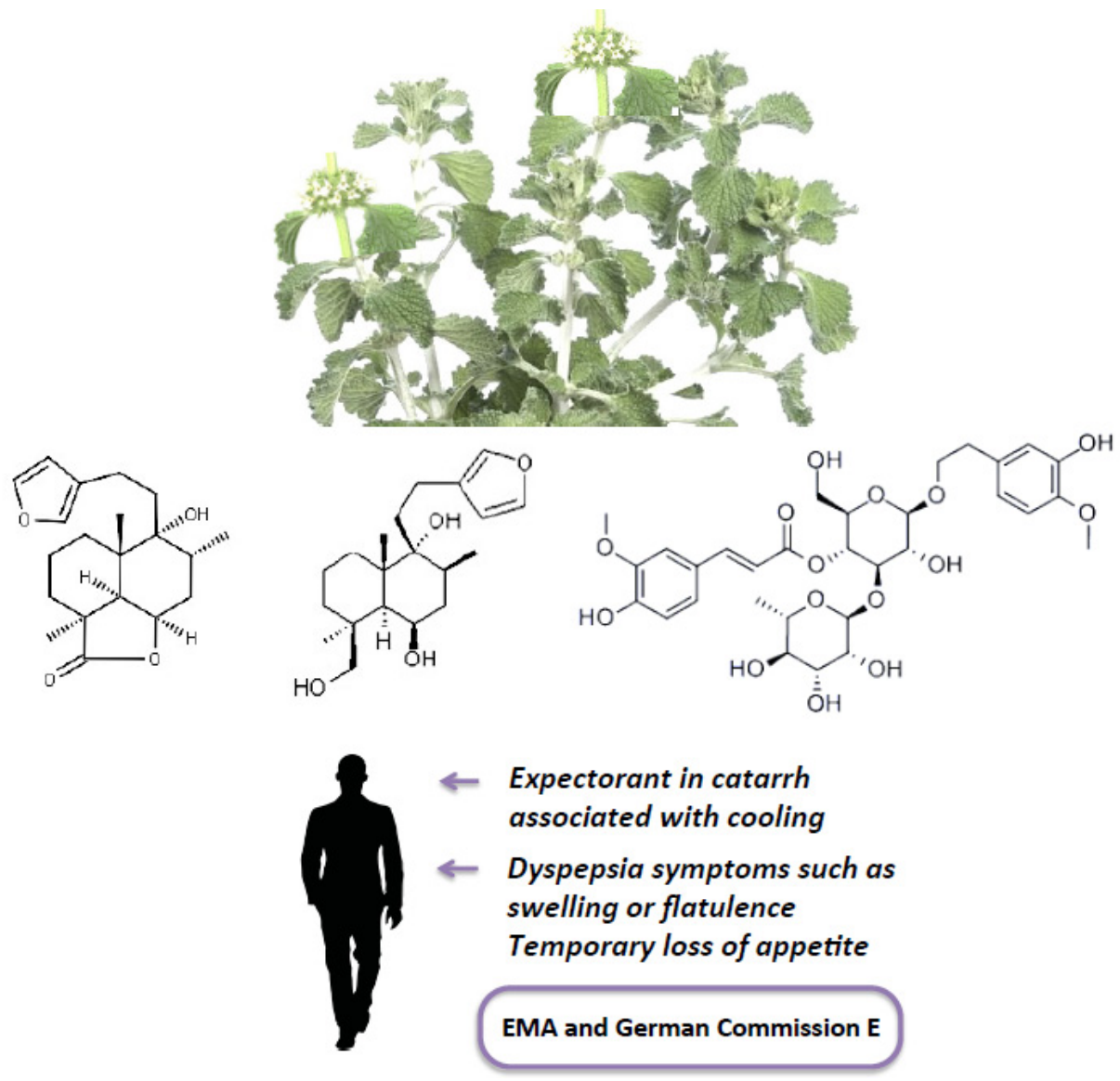

Figure 1. Top, photograph of the aerial part of Marrubium vulgare L.; Middle, marrubiin, marrubiol (both diterpenes), and martinoside (a phenylpropanoid), three of the plant's active compounds; Bottom, the European Medicine Agency (EMA) and German Commission E approved indications for the aerial part of Marrubium vulgare L.

Diabetes mellitus is a metabolic disease characterized by chronic hyperglycemia resulting from defects in insulin secretion, insulin action, or both. Diabetes mellitus type 2 (DM2), known as adult type or non-insulin-dependent diabetes mellitus, is treated by controlling the diet and oral hypoglycemic drugs [6]. In 2004, more than 120 million people in the world had diabetes. In 2015, there were approximately 415 million people with diabetes, and this is projected to increase to 642 million by 2040 (International Diabetes Federation atlas, 2015). In Mexico, DM2 affects 8.2\% of the population between 20 and 69 years old and has the highest mortality rate of chronic degenerative diseases, representing $16.7 \%$ of deaths [7].

$M$. Vulgare L. has been reported to be used in the treatment of diabetes in traditional medicine in Mexico [8] and central Morocco [6], and scientific studies have revealed through in vivo research the hypoglycemic effect of this plant, supporting its traditional use in diabetes mellitus control [9].

\section{Preclinical In Vivo Observations: The Starting Point}

Initial studies showed that horehound infusion (132 $\mathrm{g}$ of the dried plant/1 L water, in a dose of $4 \mathrm{~mL} / \mathrm{kg}$ body weight) decreased the glucose curve significantly when a $50 \%$ dextrose solution $(4 \mathrm{~mL} / \mathrm{kg}$ of weight) was administered [10].

Years later, the methanolic extract of the top parts of M. vulgare L. was also evaluated for the same purpose [11], and $500 \mathrm{~g}$ of the aerial part was homogenized with methanol for $15 \mathrm{~min}$, three times each with $1000 \mathrm{~mL}(500 \mathrm{~g} / 1 \times 3 \mathrm{~L})$, followed by distillation of the solvent under reduced pressure. The percentage yield was calculated as $12 \%$. In this case, diabetes was induced in rats 
through streptozotocin (in $0.1 \mathrm{M}$ sodium citrate buffer, $\mathrm{pH}$ 4.5) injected intraperitoneally at a dose of $55 \mathrm{mg} / \mathrm{kg}$, as a single dose. The diabetic rats orally received the extract of $M$. vulgare in a dose of $500 \mathrm{mg}$ dry extract $/ \mathrm{kg}$ of weight in a $1 \%$ CMC-Na vehicle once a day, starting on the 11th day. The oral administration of the M. vulgare extract significantly reduced the plasma glucose level after three days by more than 7\% (curiously, glibenclamide has no effect here). After 14 days, the reduction was marked, reaching $42 \%$ compared to the control values of the diabetic group. The plasma glucose level was reduced in the glibenclamide group by $31 \%$ compared to the control values of the diabetic group on the 28th day.

In 2012, Boudjelal et al. [9] proved through preclinical in vivo trials the hypoglycemic and hypolipidemic effects in diabetic albino rats $(180-200 \mathrm{~g})$ fed ad libitum with a pellet diet and water, kept and maintained under laboratory conditions of temperature and light $\left(24 \pm 1{ }^{\circ} \mathrm{C}\right.$ and a $12 \mathrm{~h}$ light/dark cycle). Rats were randomly divided into six groups and injected intraperitoneally with a single injection of alloxan monohydrate $(150 \mathrm{mg} / \mathrm{kg})$ to cause hyperglycemia and fasting blood glucose levels greater than $300 \mathrm{mg} / \mathrm{dL}$.

The extract of M. Vulgare administered was prepared by boiling $6 \mathrm{~g}$ of the aerial parts of the plant, dried at room temperature in the dark and ground to a powder, in $25 \mathrm{~mL}$ of distilled water for $15 \mathrm{~min}$, the mixture of which was then left to reach room temperature and filtrated. Extracts in a dose of 100, 200 , or $300 \mathrm{mg} / \mathrm{kg}$ of body weight were orally administered twice daily for 15 days. The positive control was glibenclamide ( $5 \mathrm{mg} / \mathrm{kg}$ of body weight); a normal control and a diabetic control were also included. A sharp decline in blood glucose levels was observed from the third day after the treatment with three doses of $M$. vulgare extracts and glibenclamide (more than $5 \%$ for $300 \mathrm{mg} / \mathrm{kg}$ of body weight, and up to $12 \%$ for glibenclamide). In particular, the highest percentage decrease of glycaemia levels was observed after 28 days for the treatments with $300 \mathrm{mg} / \mathrm{kg}$ of body weight of Marrubium infusion $(-62.55 \%)$ and the positive control glibenclamide $(-65.90 \%)$. Serum glucose, total lipids, triglycerides, and total cholesterol decreased after the administration of $M$. vulgare extract in all doses without attaining the values of the normal control. The effect was similar to that observed with the positive control, glibenclamide. The authors attribute these results to a stimulation of insulin secretion from beta cells of islets and/or inhibition of insulin degradation processes due to the high content of flavonoids in the drug (15.53 mg quercetin equivalent/g of dry plant material).

In both studies, there were no physical signs of toxicity, such as writhing, gasping, palpitation and respiratory rate, or mortality in the rats. The rats treated with different doses of $M$. vulgare did not show any drug-induced behavioral disorders.

\section{From Animals to Humans: The Clinical Trial Issue for Herbal Medicine}

More than 10 years ago, Wolsko and coworkers [12] stated that poor quality control in the United States was not surprising, given the US regulatory environment as dictated by the Dietary Supplement Health and Education Act of 1994. The same could be applied nowadays, for the United States as well as for the European Union. There is still currently no minimum standard of practice for manufacturing dietary supplements, no premarket safety or efficacy studies are needed, and dietary supplements do not need approval from the Food and Drug Administration (FDA) or the European Medicine Agency (EMA) before they are marketed. It continues to be purely the manufacturers' responsibility to ensure that supplements are safe and labeled properly before marketing. The FDA or the EMA (coordinated with the agency of each member state) can take action to restrict a product's use only after it has been shown that a dietary supplement is unsafe, sometimes years later, when it has taken the lives or has cost the health of innocent people. In the absence of evidence to the contrary, herbal supplements used in clinical trials have the same poor quality as demonstrated in the marketplace as a whole. This fact, linked with the number of pharmacognosy drugs of the same species and the different treatments being undergone, makes it very difficult if not impossible to establish valid conclusions that are not contradictory to what has been reported before in animals. 
For the Marrubium vulgare L. herb, while some articles describe and sustain the ethnopharmacological use [13], only one clinical trial can be found in the scientific literature up to date [7]. This is striking given that, in 2015, preparations of this species were the best-selling herbal dietary supplements, reaching approximately $\$ 106$ million in retail sales [14]. This randomized, double-blind, and controlled clinical trial was conducted to evaluate the clinical effect produced by its aqueous extract on type 2 non-controlled diabetes mellitus. The verum product consisted of fresh M. vulgare L. leaves that were dried under environmental temperatures and protected from direct light and then milled. Ethylene oxide was used for sterilization. Patients had to prepare the treatment immediately before administration. A 1-g filter-paper envelope was placed in a cup of boiling water for $5 \mathrm{~min}$. M. vulgare L. extract was administered three times a day, before every meal. The infusion was analyzed through HPLC with UV detection at $255 \mathrm{~nm}$ only for chlorogenic acid determination. This compound was not found in the extract.

Outpatients of either sex, between 30 and 60 years old, who had been diagnosed with type 2 diabetes no more than five years earlier, were selected. All patients were under medical treatment but showing a fasting blood glucose $>140 \mathrm{mg} / \mathrm{dL}$. As usual, patients affected with diabetes complications or nephropathy, pregnant women, patients with gestational diabetes, and hospitalized patients were not selected. In this study, insulin-dependent or type I diabetics were excluded, and, for comfort and to assure results, people who needed to travel frequently were also not selected. A total of 43 patients were recruited, and 21 received an M. vulgare L. infusion. The other 22 received a Cecropia obtusifolia extract. All patients showed treatment adherence, evaluated by counting the used dosages.

The study was carried out for 21 days. Prior to infusion administration, every seven days and after the clinical trial, the fasting determination of glucose, cholesterol, triglycerides, urea, creatinine, and uric acid in blood was carried out using automatic equipment (Autolab) with standardized techniques by a certified external laboratory.

In this study, effectiveness was considered a decrease in the basal concentration of glucose, cholesterol, or triglycerides by at least $25 \%$. M. vulgare L. caused that effect in only two of the 21 patients $(9.52 \%)$. The mean of plasma glucose level was reduced by $0.64 \%$, and that of cholesterol and triglycerides by $4.16 \%$ and $5.78 \%$, respectively. These results were disappointing.

\section{Some Result Considerations Must Be Kept in Mind: Paving the Way for Future Actions}

Nevertheless, some considerations must be taken into account. First of all, as the authors state, a crude extract was evaluated, with a similar preparation to that used in traditional medicine. As previously described, effective results on animal models were obtained after the administration of specific extracts, available after processing crude plant material with different methods. The effect of preparation methods on composition or content (as well as on undesired ingredients) is not fully understood. The same applies for therapeutic activity. Also, the administration route influences the bioavailability, pharmacological activity, and clinical effectiveness of a phytotherapeutic preparation. Previously, clinical studies could only demonstrate observations if the botanic drug material and the study design were rationally based on that basis.

What is important here is that 6-octadecynoic acid, a fatty acid with a triple bond found in Marrubium vulgare L., exhibits PPAR $\gamma$ agonist activity by directly binding to helix 12 through the conformational change of the $\Omega$ loop. Compounds with PPAR $\gamma$ agonist activity have been clinically used for treatment of type 2 diabetes by improving insulin resistance [15]. However, it is only found in the organic (methanolic) extract of the aerial parts (tops, leaves, and flowers), as fatty acids are not soluble in water infusion. It is not difficult to propose that, between others, there may be a presumable relation between the efficacy of the methanolic extract in mice models/lack of efficacy as an aqueous extraction and the presence/absence of 6-octadecynoic acid.

Despite this, as we previously stated [16], a characterized compound with a perfectly defined mechanism of action at a particular dose fulfills the negative requirements (such as toxicity) inherited from classical pharmacology. However, new trends suggest an integrative approach in which a 
wide variety of compounds act on multiple targets together to produce a final action through a balance resulting from minor changes (synergy); something different is not expected here. Diterpenes, flavonoids, and phenylpropanoid esters may also play a role in the antidiabetic activity or in the diabetes concomitant effects as on animal models.

No less important is a diligent analysis of the dose translation from animals to humans, if possible with recognized recommendations (i.e., FDA, EMA, or Commission E if available). Elberry and colleagues [11] administered to rats $500 \mathrm{mg}$ of dried extract (as previously described) per $\mathrm{kg}$ of weight. For an average person (weighing $60 \mathrm{~kg}$ ), this dosage correlates with a dose of $81 \mathrm{mg} / \mathrm{kg}$ of weight. Taking into account the drug/extraction ratio, almost $39 \mathrm{~g}$ of the herbal substance (crude drug) is needed, which is impossible to achieve for an individual administration (the EMA recommends a 1-2 $\mathrm{g}$ dose of the cut drug, and the German Commission E recommends a 4-5 g dose of the fresh/dried plant material per day). Considering the hypothesis that 6-octadecynoic acid is the compound primarily involved in the antidiabetic activity and available in sufficient amounts of raw material, these results reveal that a more efficient extraction method should be developed (ethyl acetate showed good results in the study by Ohtera et al. [15], but possible toxicity risks must be abolished before achieving clinical trials with EtOAc extracts).

For example, we proposed that the extract prepared by El Bardai et al. [17,18] was obtained by aqueous infusion ( $5 \mathrm{~g}$ air parts $/ 100 \mathrm{~mL}$ of water, yield after lyophilization) with a drug: extract ratio (DER) 6.2:1 and performance 13\%. This extract minimizes possible toxicity due to organic solvents, allows oral administration, and makes feasible the fulfilment of the recommended therapeutic range, which allows a maximum amount of $6 \mathrm{~g}$ per drug per day.

Finally, it is important to notice the slighter side effects (described by one in every four patients) in the clinical trial, including nausea, oral dryness, sialorrhea, dizziness, and anorexia, although they were not adverse enough to necessarily cause a withdrawal from the study [7]. These results and the acquired experience in the traditional intake of the water infusion of Marrubium vulgare L. can be considered safe. In spite of this, the number of patients, as is usual in clinical trials of herb preparations, was reduced, and the establishment of general conclusions is therefore almost impossible.

Conflicts of Interest: The authors declare that there is no conflict of interest.

\section{References}

1. Kahkeshani, N.; Gharedaghi, M.; Hadjiakhoondi, A.; Sharifzadeh, M. Antinociceptive effect of extracts of Marrubium astracanicum Jacq. aerial parts. Avicenna J. Phytomed. 2017, 7, 73-79. [PubMed]

2. Mittal, V.; Nanda, A. Intensification of marrubiin concentration by optimization of microwave-assisted (low $\mathrm{CO}_{2}$ yielding) extraction process for Marrubium vulgare using central composite design and antioxidant evaluation. Pharm. Biol. 2017, 55, 1337-1347. [CrossRef] [PubMed]

3. Aouni, R.; Attia, M.B.; Jaafoura, M.H.; Bibi-Derbel, A. Effects of the hydro-ethanolic extract of Marrubium vulgare in female rats. Asian Pac. J. Trop. Med. 2017, 10, 160-164. [CrossRef] [PubMed]

4. Villanueva, R.J.; Esteban, M.J. An Insight into a Blockbuster Phytomedicine; Marrubium vulgare L. Herb. More of a Myth than a Reality? Phytother. Res. 2016, 30, 1551-1558. [CrossRef] [PubMed]

5. Garjani, A.; Tila, D.; Hamedeyazdan, S.; Vaez, H. An investigation on cardioprotective potential of Marrubium vulgare aqueous fraction against ischemia-reperfusion injury in isolated rat heart. Folia Morphol. (Warsz) 2015. [CrossRef] [PubMed]

6. Barkaoui, M.; Katiri, A.; Boubaker, H.; Msanda, F. Ethnobotanical survey of medicinal plants used in the traditional treatment of diabetes in Chtouka Ait Baha and Tiznit (Western Anti-Atlas), Morocco. J. Ethnopharmacol. 2017, 198, 338-350. [CrossRef] [PubMed]

7. Herrera-Arellano, A.; Aguilar-Santamaria, L.; Garcia-Hernandez, B.; Nicasio-Torres, P. Clinical trial of Cecropia obtusifolia and Marrubium vulgare leaf extracts on blood glucose and serum lipids in type 2 diabetics. Phytomedicine 2004, 11, 561-566. [CrossRef] [PubMed] 
8. Argueta, V.A.; Cano, L.M.; Rodarte, M.E. (Eds.) Atlas de las Plantas de la Medicina Tradicional Mexicana; Instituto Nacional Indigenista: Mexico DF, República de Mexico, 1994; Volume 3. Available online: www.medicinatradicionalmexicana.unam. $\mathrm{mx} /$ monografia.php? $=3 \& \mathrm{t}=$ Marrubio\&id=76201 (accessed on 29 July 2017).

9. Boudjelal, A.; Henchiri, C.; Siracusa, L.; Sari, M. Compositional analysis and in vivo anti-diabetic activity of wild Algerian Marrubium vulgare L. infusion. Fitoterapia 2012, 83, 286-292. [CrossRef] [PubMed]

10. Roman Ramos, R.; Alarcon-Aguilar, F.; Lara-Lemus, A.; Flores-Saenz, J.L. Hypoglycemic effect of plants used in Mexico as antidiabetics. Arch. Med. Res. 1992, 23, 59-64. [PubMed]

11. Elberry, A.A.; Harraz, F.M.; Ghareib, S.A.; Gabr, S.A. Methanolic extract of Marrubium vulgare ameliorates hyperglycemia and dyslipidemia in streptozotocin-induced diabetic rats. Int. J. Diabetes Mellit. 2015, 3, 37-44. [CrossRef]

12. Wolsko, P.M.; Solondz, D.K.; Phillips, R.S.; Schachter, S.C. Lack of herbal supplement characterization in published randomized controlled trials. Am. J. Med. 2005, 118, 1087-1093. [CrossRef] [PubMed]

13. Ballero, M.; Sotgiu, A.M.; Piu, G. Empirical administration of preparations of Marrubium vulgare in the asthmatic syndrome. Biomed. Lett. 1998, 57, 31-36.

14. Izzo, A.A.; Hoon-Kim, S.; Radhakrishnan, R.; Williamson, E.M. A Critical Approach to Evaluating Clinical Efficacy, Adverse Events and Drug Interactions of Herbal Remedies. Phytother. Res. 2016, 30, 691-700. [CrossRef] [PubMed]

15. Ohtera, A.; Miyamae, Y.; Nakai, N.; Kawachi, A. Identification of 6-octadecynoic acid from a methanol extract of Marrubium vulgare L. as a peroxisome proliferator-activated receptor gamma agonist. Biochem. Biophys. Res. Commun. 2013, 440, 204-209. [CrossRef] [PubMed]

16. Villanueva, J.R.; Esteban, J.M.; Villanueva, R.L. Solving the puzzle: What is behind our forefathers' anti-inflammatory remedies? J. Int. Ethnopharmacol. 2017, 6, 128-143. [CrossRef] [PubMed]

17. El Bardai, S.; Hamaide, M.C.; Lyoussi, B.; Quetin-Leclercq, J.; Morel, N.; Wibo, M. Marrubenol interacts with the phenylalkylamine binding site of the L-type calcium channel. Eur. J. Pharmacol. 2004, 492, 269-272. [CrossRef] [PubMed]

18. El Bardai, S.; Lyoussi, B.; Wibo, M.; Morel, N. Comparative study of the antihypertensive activity of Marrubium vulgare and of the dihydropyridine calciumantagonistamlodipine in spontaneously hypertensive rat. Clin. Exp. Hypertens. 2004, 26, 465-474. [CrossRef] [PubMed] 